\title{
Protective effect of transplanted bone marrow-derived mesenchymal stem cells on pancreatitis-associated lung injury in rats
}

\author{
LIE WANG, XIAO-HUANG TU, PENG ZHAO, JING-XIANG SONG and ZHONG-DONG ZOU
}

Department of General Surgery, Fuzhou General Hospital of Nanjing Military Region, Fuzhou, Fujian 350025, P.R. China

Received January 18, 2012; Accepted April 10, 2012

DOI: $10.3892 / \mathrm{mmr} .2012 .922$

\begin{abstract}
Severe acute pancreatitis (SAP) is initiated by the premature activation of digestive enzymes within the pancreatic acinar cells, leading to self-digestion and inflammatory responses in pancreatic ductal cells, thus giving rise to systemic inflammatory response syndrome (SIRS). The most common and serious SIRS is pancreatitis-associated lung injury, and inflammatory mediators play an important role in its pathogenesis. Bone marrow-derived mesenchymal stem cells (MSCs) are differentiated into alveolar endothelial cells to replace the damaged alveolar endothelial cells and inhibit inflammatory response in the injured lung tissues. In this study, we aimed to investigate the therapeutic effect of bone marrow-derived MSCs in rats with pancreatitis-associated lung injury. Experimental SAP was induced by a retrograde injection of 5\% sodium taurocholate into the biliopancreatic duct of 75 male Sprague-Dawley rats, which were divided into the SAP group $(n=25)$, the MSC group $(n=25)$ and the sham-operated group $(n=25)$ to explore the pathology and function of lung tissues and the regulation of inflammatory mediators. Pulmonary edema was estimated by measuring water content in the lung tissues. Pulmonary myeloperoxidase (MPO) activity was detected using spectrophotometry. Serum amylase was detected using the Automatic Biochemistry Analyzer. Tumor necrosis factor- $\alpha$ (TNF- $\alpha$ ) and substance $\mathrm{P}(\mathrm{SP}) \mathrm{mRNA}$ levels were determined by quantitative reverse transcriptase-polymerase chain reaction. Our results showed that serum amylase activity was significantly decreased in the MSC group compared to the SAP group. Pulmonary edema was significantly diminished $(\mathrm{p}<0.05)$ in the MSC group compared to the SAP group. Typical acute lung injury was observed in the SAP group, and the pathological changes
\end{abstract}

Correspondence to: Dr Xiao-Huang Tu, Department of General Surgery, Fuzhou General Hospital of Nanjing Military Region, 156 West Erhuan Road, Fuzhou, Fujian 350025, P.R. China

E-mail: tuxiaohuang@yahoo.cn

Key words: mesenchymal stem cells, severe acute pancreatitis, pancreatitis-associated lung injury, substance $\mathrm{P}$, tumor necrosis factor- $\alpha$ were mild in the MSC group. The expression of TNF- $\alpha$ and SP mRNA in lung tissue was diminished in the MSC group compared to the SAP group. In conclusion, MSC transplantation attenuates pulmonary edema and inflammation, and reduces the mRNA expression of TNF- $\alpha$ and SP in pancreatitis-associated lung injury.

\section{Introduction}

Acute pancreatitis (AP) is an inflammatory disease involving normal pancreatic gland that exhibits a variety of clinical manifestations. Although mild AP has a low morbidity and mortality rate, severe acute pancreatitis (SAP) is a necrotizing disease involving remote organ systems. SAP occupies $20 \%$ of the patients with AP, and 15-25\% of SAP patients will eventually die (1). SAP is initiated by the premature activation of digestive enzymes (trypsin, elastase and lipase) within the pancreatic acinar cells, leading to self-digestion of pancreatic tissue (2). During the early phase of SAP, inflammatory responses occur in the ductal cells and give rise to systemic inflammatory response syndrome (SIRS), leading to long-distance organ damage and multiple organ dysfunction syndrome (MODS) (3). The most common and serious SIRS is pancreatitis-associated lung injury, which is characterized by increased endothelial and epithelial barrier permeability, with exudate leaking into the alveolar space and interstitial lung, thus leading to pulmonary edema and gas exchange dysfunction (4). As shown in a previous study, inflammatory mediators play an important role in the pathogenesis of pancreatitis-associated acute lung injury (ALI). These mediators include tumor necrosis factor- $\alpha$ (TNF- $\alpha$ ), interleukin (IL)-1 $\beta,-6$ and -10 , granulocyte macrophage-colony stimulating factor (GM-CSF) and neuropeptide substance $\mathrm{P}$ (SP) (5). All of these mediators represent potential targets for therapeutic intervention.

Mesenchymal stem cells (MSCs) are multipotent adult stem cells, mainly found in the bone marrow, that differentiate into a variety of cell types, including chondrocytes, myoblasts, endothelial, epithelial, nerve and alveolar epithelial cells. Bone marrow-derived MSCs possess immunomodulatory properties and are differentiated into alveolar endothelial cells to replace damaged alveolar endothelial cells. Furthermore, an allograft of MSCs has been shown to inhibit the inflammatory response and to decrease collagen content in the injured lung tissues, 
thus diminishing the incidence of pulmonary fibrosis (6). All these advantages are beneficial to the cell replacement therapy for the treatment of diseases of the respiratory system.

In this study, we explored the protective role of MSCs in rats with SAP and the possible mechanisms involved. We also investigated the pathology and function of lung tissue in rats with SAP, as well as the regulation of inflammatory mediators and possible mechanisms involved.

\section{Materials and methods}

Experimental animals. Sprague-Dawley (SD) rats, weighing 250-300 g [Batch No. SCXK (Shanghai) 2007-0005], were provided by the Shanghai SLK Experimental Animal Co. Two rats of 4 weeks of age, weighing 60-80 g were used for the isolation of bone marrow-derived MSCs. The guidelines for animal ethics were followed in all the care and handling of the animals.

Cultivation and identification of MSCs. MSCs were isolated from bone marrow. The male SD rats of 4 weeks of age were sacrificed by cervical dislocation, and their bilateral lower limb was amputated under sterile and anaesthetic conditions. The tibia and femur were exposed with the muscles knocked out. The bone marrow cavity was washed with DMEM-F12 nutrient solution until the whitening of the backbone. The bone marrow cell suspension was acquired under sterile conditions in mixed nutrient medium with $10 \%$ fetal calf serum and DMEM-F12, and was inoculated with DMEM-F12 nutrient solution at $6 \times 10^{5} / \mathrm{cm}^{2}$ density with the supernatant discarded. The bone marrow cells were cultured by differential adherence methods, and the situations of cell adherence were observed with no exchange of medium within $48 \mathrm{~h}$. When the cells grew to $90 \%$ confluence at the bottom of the culture flask, they were passaged at 1:2 or 1:3 according to the cell growth. At the third generation, cells were harvested, digested with trypsin and counted for reserve. The cellular identification of the expression of MSC surface makers, including CD90, CD29, CD34 and CD45, was performed by flow cytometry. The third generation MSCs were induced to differentiate into adipogenic and osteoblast cells for identification. These third generation MSCs were used for the following transplant experiments.

Experimental model. SD rats, weighing 250-300 g, were selected for the experiment. AP was induced by sodium taurocholate (7). Rats were anesthetized by an intraperitoneal injection of $3 \%$ pentobarbital sodium at a dose of $30 \mathrm{mg} / \mathrm{kg}$. The biliopancreatic duct was cannulated through the duodenum, and the hepatic duct was closed with a small bulldog clamp. The SAP model was established by a retrograde infusion of $5 \%$ sodium taurocholate (Sigma, St. Louis, MO, USA) into the biliopancreatic duct. In the sham-operated group (SO), SD rats received a retrograde infusion of sterile saline.

Experimental design. Seventy-five male SD rats were randomly divided into the SO group $(n=25)$, SAP group $(n=25)$ and MSC group $(n=25)$. Rats with AP were randomly divided into SAP group and MSC treatment group, which, $2 \mathrm{~h}$ after the surgery, were injected with $1 \mathrm{ml}$ medium (SAP group) or $1 \mathrm{ml}$ medium with cell suspension ( $\left.1 \times 10^{6} \mathrm{MSCs}\right)$ (MSC group). Rats in the $\mathrm{SO}$ group were injected with medium with an equivalent volume at the same time-point. Rats were sacrificed 1, 3, 6, 12 and $24 \mathrm{~h}$ after the establishment of the model, and then the serum amylase (AMS) levels, IL-1, IL-10, TNF- $\alpha$, macrophage inflammatory protein (MIP) and other inflammation factors were detected. Pancreatic and lung tissues were harvested.

Cell marking. Third generation MSCs were added with sterile DAPI (final concentration $50 \mathrm{~g} / \mathrm{l}$ ) and incubated at $37^{\circ} \mathrm{C}$ for $12 \mathrm{~h}$. After repeated washing with PBS to remove DAPI, the cells were collected after one more centrifugation. DMEMF12 medium $(1 \mathrm{ml})$ supplemented with $10 \%$ fetal calf serum containing $1 \times 10^{6}$ MSCs was injected into the rats with SAP through the caudal vein at $2 \mathrm{~h}$.

Quantitative reverse transcriptase-polymerase chain reaction $(R T-P C R)$. The total RNA was extracted with the use of a TRIzol kit (Invitrogen, Carlsbad, CA, USA) and converted to cDNA with a first strand cDNA synthesis kit (Fermentas, Burlington, Canada). Quantitative RT-PCR was performed using SYBR-Green SuperMix-UDG (Invitrogen). The primer sequences used for PCR were: TNF- $\alpha$ forward, 5'-ACTCCCA GAAAAGCAAGCAA-3' and reverse, 5'-CGAGCAGGAA TGAGAAGAGG-3'; SP forward, 5'-AGAGGAAATCGGTG CCAACG-3' and reverse, 5'-TAATCCAAAGAACTGCT GAGG-3'; $\beta$-actin forward, 5'-CACCCGCGAGTACAA CCTTC-3' and reverse, 5'-CCCATA CCCACCATCACACC-3'. PCR amplification was performed at an annealing temperature of $50^{\circ} \mathrm{C}$ for $2 \mathrm{~min}$ (UDG incubation), at $95^{\circ} \mathrm{C}$ for $2 \mathrm{~min}$, followed by 40 cycles of denaturing at $95^{\circ} \mathrm{C}$ for $20 \mathrm{sec}$ and annealing at $60^{\circ} \mathrm{C}$ for $30 \mathrm{sec}$. All reactions were performed in triplicate. Melting curve analysis was constructed to ensure the specificity of quantitative PCR. Data were expressed as TNF- $\alpha$ or SP mRNA levels relative to the $\beta$-actin gene.

Detection for wet-to-dry ratio of lung tissue. Water content in lung tissue samples was measured to estimate the severity of pulmonary edema. As soon as the rats were sacrificed, their right middle lobe lung tissues were removed. Fresh lung tissue samples were weighed. After saline rinse, the samples were placed in an oven at $160^{\circ} \mathrm{C}$ for $48 \mathrm{~h}$ and dried to constant weight and were then reweighed. The moisture content of the lung was expressed as wet weight/dry weight, presenting the degree of pulmonary edema.

Observation of lung morphology. Lung tissue rat samples were fixed with $4 \%$ paraformaldehyde, and embedded in paraffin. The paraffin-embedded tissues were then sectioned into slices (5 $\mu \mathrm{m}$ thick). After H\&E staining, the morphological changes in lung tissue were observed under a microscope.

Determination of lung myeloperoxidase (MPO) activity. Lung tissue samples were homogenized by freeze thawing and sonication. The supernatant after centrifugation was used for the assay. In $20 \mu \mathrm{l}$ of supernatant, $10 \mu \mathrm{l}$ of tetramethylbenzidine (final concentration, $1.6 \mathrm{mmol} / \mathrm{l}$ ) and $70 \mu \mathrm{l}$ of $\mathrm{H}_{2} \mathrm{O}_{2}$ (final concentration, $3.0 \mathrm{mmol} / \mathrm{l}$ ) were added to make reaction solution. MPO activity was assessed at the wavelength of $630 \mathrm{~nm}$ in a spectrophotometer for $2 \mathrm{~min}$. The absorbance difference was recorded at the first 30 and $90 \mathrm{sec}$, and this value repre- 
A

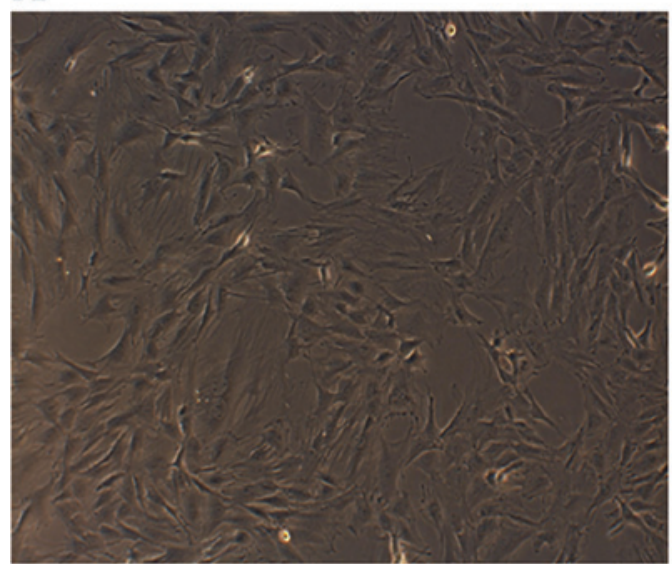

Isolated MSCs
B

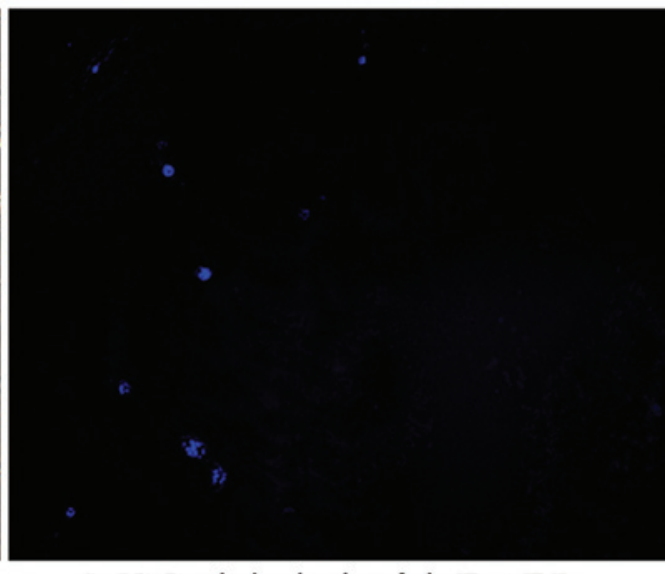

MSCs labeled with DAPI

Figure 1. Third generation mesenchymal stem cells (MSCs). (A) The isolated MSCs were spindle-shaped, forming spiral-like colonies (magnification, x200). (B) Third generation MSCs labeled with DAPI the day before the allograft.

sents the changes in MPO enzyme activity in the granules of polymorphonuclear neutrophils (PMNs).

Measurement of serum AMS levels. Serum AMS levels were measured with an Automatic Biochemistry Analyzer CL-7300 (Shimadzu Corp., Kyoto, Japan) to confirm the successful induction of SAP.

Statistical analysis. Data are expressed as the means \pm SD. ANOVA was used to analyze the differences between the groups. All statistical analyses were performed using the SPSS software (version 13.0 for Windows). $\mathrm{P}<0.05$ denoted statistically significant differences.

\section{Results}

Observation of MSCs. The third generation MSCs were observed under an inverted microscope. A small amount of cell adhesion was found at $24 \mathrm{~h}$ after incubation in a flat-bottom plate, which was significantly increased when the incubation time was prolonged to $48 \mathrm{~h}$. Most cells were spindle-shaped when observed under a microscope. The primary generation grew in lumps and reached $90 \%$ confluence after incubation for 2 weeks (Fig. 1A).

Tracing of MSCs by DAPI. The third generation MSCs were incubated with DAPI in the culture medium the day before the allograft, followed by the sacrificing of rats and the isolation of lung tissue. The tissue samples were observed under a microscope, and the blue stained cells were immigrated MSCs (Fig. 1B).

Detection of surface markers on MSCs by flow cytometry. The cell surface markers on third generation MSCs were detected by flow cytometry. The positive rates of CD90 and CD29 were 98.6\% (Fig. 2A) and 97.5\% (Fig. 2B), respectively. However, the expression of CD34 and CD45 in MSCs was low, with positive rates of $0.56 \%$ (Fig. 2C) and $0.79 \%$ (Fig. 2D), respectively. This demonstrated that the purity of the MSCs was $>95 \%$.
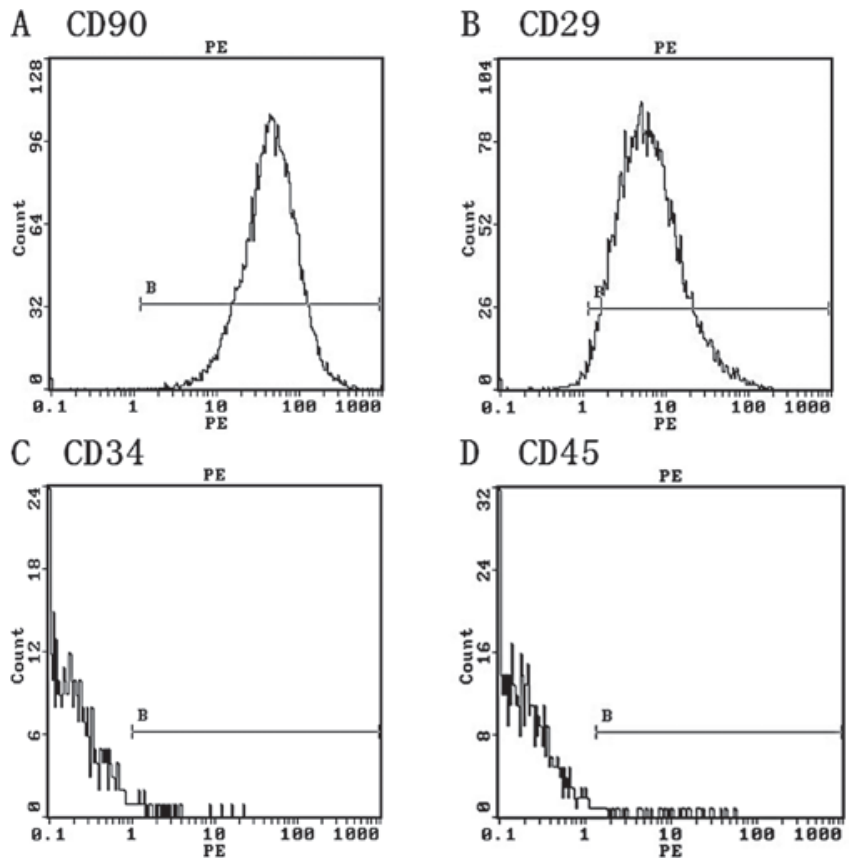

Figure 2. (A) The proportion of the $\mathrm{CD} 90^{+}$cells was $98.6 \%$; (B) the proportion of CD29+ cells was $97.5 \%$; (C) the proportion of $\mathrm{CD}^{+} 4^{+}$cells was $0.56 \%$; (D) the proportion of $\mathrm{CD}^{4} 5^{+}$cells was $0.79 \%$.

MSC transplantation attenuates pulmonary edema and inflammation in rats with SAP. In the SAP group, the pancreatitis-associated ALI was demonstrated by histology, characterized by alveolar edema, hemorrhaging, pulmonary interstitial edema, inflammatory cell infiltration, thicker alveolar septum and damage to the normal structure of the lung tissues. After MSC transplantation, the alveolar structure had improved, with thin walls, less infiltration of inflammatory cells and decreased tissue edema (Fig. 3).

Pulmonary edema was examined by measuring the water content in the lung tissue samples and expressed as lung wetto-dry ratio. The lung wet-to-dry ratio showed no significant difference at $1 \mathrm{~h}$ after MSC transplantation, but was signifi- 


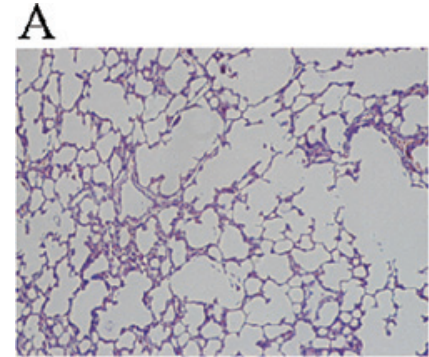

SAP $3 \mathrm{~h}$

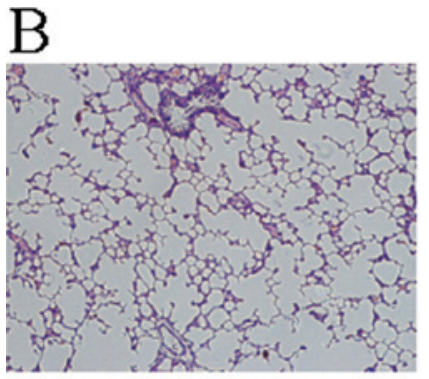

MSCs $3 \mathrm{~h}$

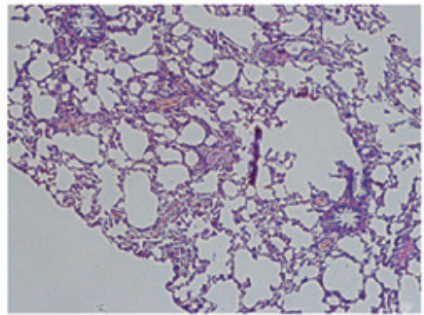

SAP $6 \mathrm{~h}$

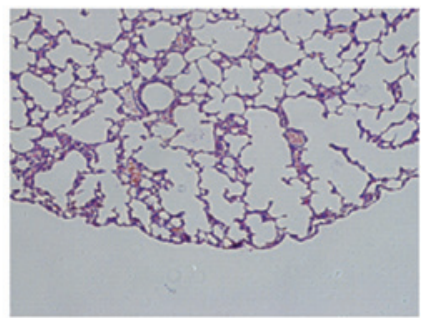

MSCs $6 \mathrm{~h}$

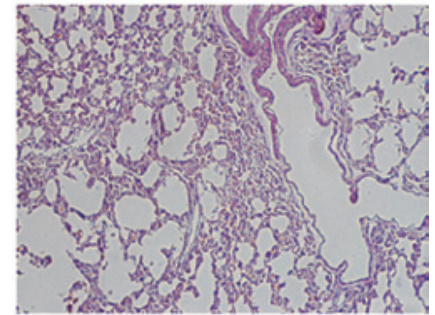

SAP $12 \mathrm{~h}$

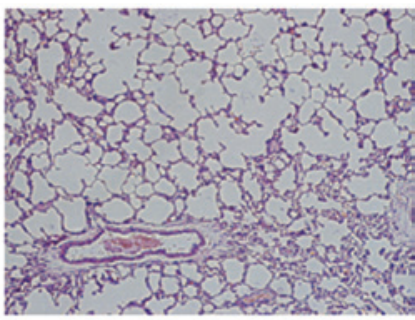

MSCs 12 h

Figure 3. Morphological changes of lung tissues in pancreatitis-associated lung injury. (A) Severe acute pancreatitis (SAP) group; and (B) mesenchymal stem cell (MSC) transplantation group at 3,6 and $12 \mathrm{~h}$ (H\&E staining; magnification, $\mathrm{x} 200$ ).

Table I. Pulmonary edema scores (lung wet-to-dry ratio) in the different groups (means \pm SD).

\begin{tabular}{lccccc}
\hline Group & $1 \mathrm{~h}$ after modeling & $3 \mathrm{~h}$ after modeling & $6 \mathrm{~h}$ after modeling & $12 \mathrm{~h}$ after modeling & $24 \mathrm{~h}$ after modeling \\
\hline SO group & $4.23 \pm 0.17$ & $5.78 \pm 0.10$ & $5.88 \pm 0.180$ & $6.69 \pm 0.13$ & $6.02 \pm 0.15$ \\
SAP group & $5.21 \pm 0.13$ & $6.23 \pm 0.18^{\mathrm{a}}$ & $6.62 \pm 0.331^{\mathrm{a}}$ & $6.95 \pm 0.42^{\mathrm{a}}$ & $6.32 \pm 0.23^{\mathrm{a}}$ \\
MSC group & $4.93 \pm 0.15$ & $5.74 \pm 0.10^{\mathrm{b}}$ & $5.85 \pm 0.160^{\mathrm{b}}$ & $6.03 \pm 0.30^{\mathrm{a}, \mathrm{b}}$ & $6.21 \pm 0.25^{\mathrm{a}, \mathrm{b}}$ \\
\hline
\end{tabular}

${ }^{\mathrm{a} C o m p a r e d ~ t o ~ t h e ~ S O ~ g r o u p, ~} \mathrm{P}<0.05$; ${ }^{\mathrm{b}}$ compared to the SAP group, $\mathrm{P}<0.05$. SO, sham-operated; SAP, severe acute pancreatitis; MSC, mesenchymal stem cell.

Table II. Changes in myeloperoxidase content in lung tissue in the different groups (means \pm SD).

\begin{tabular}{lccccc}
\hline Group & $1 \mathrm{~h}$ after modeling & $3 \mathrm{~h}$ after modeling & $6 \mathrm{~h}$ after modeling & $12 \mathrm{~h}$ after modeling & $24 \mathrm{~h}$ after modeling \\
\hline SO group & $1.01 \pm 0.05$ & $1.03 \pm 0.06$ & $1.06 \pm 0.07$ & $1.08 \pm 0.11$ & $1.05 \pm 0.08$ \\
SAP group & $1.26 \pm 0.10$ & $3.60 \pm 0.30^{\mathrm{a}}$ & $8.62 \pm 0.58^{\mathrm{a}}$ & $10.82 \pm 0.59^{\mathrm{a}}$ & $9.76 \pm 0.42^{\mathrm{a}}$ \\
MSC group & $1.18 \pm 0.06$ & $2.25 \pm 0.11^{\mathrm{a}, \mathrm{b}}$ & $4.26 \pm 0.30^{\mathrm{a}, \mathrm{b}}$ & $3.12 \pm 0.49^{\mathrm{a}, \mathrm{b}}$ & $3.89 \pm 0.38^{\mathrm{a}, \mathrm{b}}$
\end{tabular}

${ }^{\mathrm{a} C}$ Compared to the SO group, $\mathrm{P}<0.05$; ${ }^{\mathrm{b}}$ compared to the SAP group, $\mathrm{P}<0.05$. SO, sham-operated; SAP, severe acute pancreatitis; MSC, mesenchymal stem cell.

cantly decreased at 3,6, 12 and $24 \mathrm{~h}$ after MSC transplantation $(\mathrm{P}<0.05)$ (Table I).

There was no significant difference in MPO activity in the lung tissue at $1 \mathrm{~h}$ between the groups. On the contrary, in the MSC group, the MPO activity was decreased significantly compared to the SAP group at $3,6,12$ and $24 \mathrm{~h}(\mathrm{P}<0.05)$ (Table II).
Serum AMS in the SAP group was significantly higher than that in the SO group at each time-point $(\mathrm{P}<0.05)$. After MSC transplantation, serum AMS decreased significantly compared to the SAP group at each time-point $(\mathrm{P}<0.01)$ (Table III).

Transplanted MSCs decrease the mRNA levels of TNF- $\alpha$ and $S P$ in lung tissues of SAP rats. The mRNA expression levels 
Table III. Serum amylase levels at each time-point in the different groups (U/l).

\begin{tabular}{lccccc}
\hline Group & $1 \mathrm{~h}$ after modeling & $3 \mathrm{~h}$ after modeling & $6 \mathrm{~h}$ after modeling & $12 \mathrm{~h}$ after modeling & $24 \mathrm{~h}$ after modeling \\
\hline SO group & $1,452 \pm 93$ & $3,463 \pm 310$ & $3,874 \pm 230$ & $3,782 \pm 382$ & $3,521 \pm 140$ \\
SAP group & $3,123 \pm 246$ & $5,509 \pm 890^{\mathrm{a}}$ & $8,800 \pm 1120^{\mathrm{a}}$ & $10,249 \pm 1,392^{\mathrm{a}}$ & $6,724 \pm 1,031^{\mathrm{a}}$ \\
MSC group & $2,956 \pm 109$ & $4,766 \pm 556^{\mathrm{a}, \mathrm{b}}$ & $5,482 \pm 887^{\mathrm{a}, \mathrm{b}}$ & $6,724 \pm 1,024^{\mathrm{a}, \mathrm{b}}$ & $3,108 \pm 228^{\mathrm{a}, \mathrm{b}}$ \\
\hline
\end{tabular}

${ }^{a}$ Compared to the control group, $\mathrm{P}<0.05 ;{ }^{\mathrm{b}}$ compared to the SAP group, $\mathrm{P}<0.05$. SO, sham-operated; SAP, severe acute pancreatitis; MSC, mesenchymal stem cell.

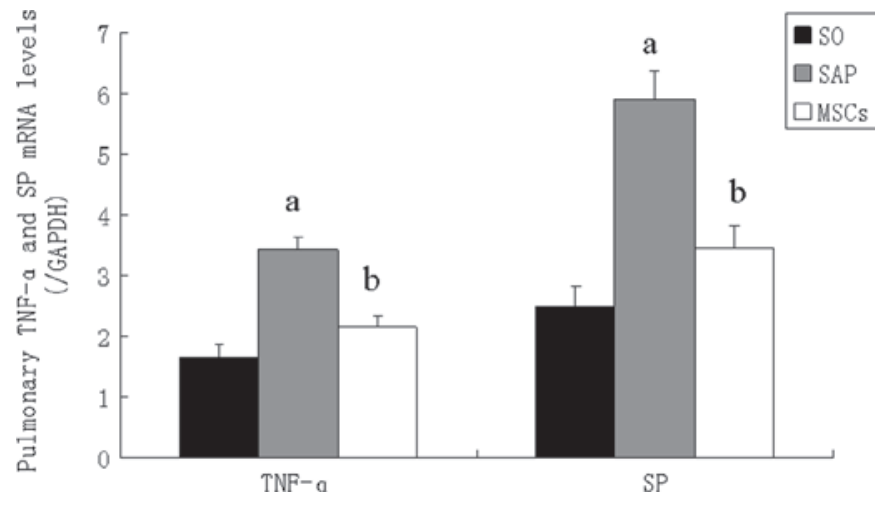

Figure 4. Effects of transplanted mesenchymal stem cells (MSCs) on tumor necrosis factor- $\alpha(\mathrm{TNF}-\alpha)$ and substance $\mathrm{P}(\mathrm{SP})$ mRNA transcription in rats. Six rats were studied in each experimental group. Results are expressed as the means $\pm \mathrm{SD}$. ${ }^{\mathrm{P}}<0.05$ vs. the sham-operated (SO) group; ${ }^{\text {b }} \mathrm{P}<0.05$ vs. the severe acute pancreatitis (SAP) group.

of TNF- $\alpha$ and SP were markedly higher in the SAP group than in the SO group. The transplanted MSCs increased the expression levels of TNF- $\alpha$ and SP mRNA in rats with SAP (Fig. 4).

\section{Discussion}

In the present study, we established an experimental model of sodium taurocholate-induced SAP that is characterized by systemic inflammation and MODS, particularly pancreatitisassociated lung injury. Compared to the controls, rats with SAP had increased pulmonary edema, higher MPO content in the lung tissue and higher serum AMS levels. The intravenous transplantation of MSCs attenuated pulmonary edema and inflammatory infiltration in the rats with SAP, and reduced the mRNA levels of TNF- $\alpha$ and SP in the lung tissues of the rats with SAP.

Pancreatitis-associated lung injury is the most frequent and serious systemic complication of SAP (8), which is characterized by pulmonary edema, inflammatory infiltration in pulmonary tissues and increased inflammatory mediators (9). Pancreatitis-associated lung injury exhibits a phenotype with diffuse alveolar damage, microvascular injury, type I pneumocyte necrosis and an influx of inflammatory cells, leading to injured endothelial and epithelial cells in lung tissues (10).

Recently, a certain study demonstrated that transplanted MSCs have strong immunoregulatory effects and reduce inflammation and damage to pancreatic tissue in a rat model of AP, as evidenced by the reduced expression of inflammatory mediators and cytokines (11). MSCs have been shown to have anti-inflammatory effects in a variety of diseases, such as inflammatory bowel disease (12), hepatitis (13) and peritonitis (14).

In our study, we found that transplanted MSCs reduced pancreatitis-associated lung injury in a rat model, attenuated pulmonary edema, and reduced inflammatory mediators in lung tissue, such as TNF- $\alpha$ and SP. TNF- $\alpha$ and SP have been introduced as two important factors in adjusting and controlling pancreatitis-associated lung injury. TNF- $\alpha$ expression plays an important role in the pathogenesis of ALI. Pancreatic inflammation-associated elastase activation induces TNF- $\alpha$-mediated lung injury, and lung injury is markedly reduced in TNF- $\alpha$-deficient animals (15). TNF- $\alpha$ also potently stimulates matrix metalloproteinase-9 (MMP-9) release from PMNs, and induces PMN transmigration and resultant alveolar-capillary leakage in SAP (16). SP is the gene product of preprotachykinin-A, a type of neural peptide with a regulatory function in different phases of inflammation. In pancreatitis-associated lung injury, the integrity of epidermal and alveolar cells in the lungs is destroyed, leading to damaged vacuolar membranes in the alveoli and leaking capillaries, and subsequently pulmonary interstitial edema. Thus, SP plays an important pro-inflammatory role in regulating the severity of AP and pancreatitis-associated lung injury (17). Our study demonstrates that MSC transplantation significantly decreases TNF- $\alpha$ and SP mRNA levels, indicating that the severity of lung injury may be attenuated in rats with SAP.

MSCs also have an antioxidant effect and promote antioxidant components, such as superoxide dismutase and glutathione peroxidase (18), exhibiting a protective function against oxidative damage-induced apoptosis (19). Considering the oxidative stress effect of MPO activity, MSCs exhibit antioxidant effects, partly through the downregulation MPO activity, in rats with SAP. Furthermore, MPO activity is a marker of local leukocyte sequestration (20). Our study suggests that MSC transplantation attenuates pancreatitis-associated lung injury by inhibiting the production of inflammatory cytokines and leukocyte infiltration in lung tissues.

MSCs have a protective effect on lung injury in diseases other than SAP $(21,22)$, indicating that MSCs have similar therapeutic targets in lung injury. However, multiple factors and inflammatory mediators participate in pancreatitisassociated lung injury. Therefore, further research is required to elucidate the exact mechanism behind the protective effect of MSCs on lung injury. A recent study showed that in chronic 
inflammation and lung injury, MSCs were converted into AT II epithelial cells, performing a tissue repair function (23). Whether this mechanism plays a role in our model requires further study.

In conclusion, MSC transplantation attenuates pulmonary edema and inflammation, and decreases the mRNA expression of TNF- $\alpha$ and SP in lung tissues of rats with pancreatitisassociated lung injury.

\section{Acknowledgements}

This study was funded by the Medical and Health Research Project of the Nanjing Military Region (No. 08Z029).

\section{References}

1. Carroll JK, Herrick B, Gipson T and Lee SP: Acute pancreatitis: diagnosis, prognosis, and treatment. Am Fam Physician 75: 1513-1520, 2007.

2. Shah AU, Sarwar A, Orabi AI, et al: Protease activation during in vivo pancreatitis is dependent on calcineurin activation. Am J Physiol Gastrointest Liver Physiol 297: G967-G973, 2009.

3. Bhatia M: Acute pancreatitis as a model of SIRS. Front Biosci 14: 2042-2050, 2009.

4. Zhou MT, Chen CS, Chen BC, Zhang QY and Andersson R: Acute lung injury and ARDS in acute pancreatitis: mechanisms and potential intervention. World J Gastroenterol 16: 2094-2099, 2010.

5. Bhatia M and Moochhala S: Role of inflammatory mediators in the pathophysiology of acute respiratory distress syndrome. J Pathol 202: 145-156, 2004.

6. Aggarwal S and Pittenger MF: Human mesenchymal stem cells modulate allogeneic immune cell responses. Blood 105: 1815-1822, 2005.

7. Pereda J, Sabater L, Cassinello N, et al: Effect of simultaneous inhibition of TNF-alpha production and xanthine oxidase in experimental acute pancreatitis: the role of mitogen activated protein kinases. Ann Surg 240: 108-116, 2004.

8. Browne GW and Pitchumoni CS: Pathophysiology of pulmonary complications of acute pancreatitis. World J Gastroenterol 12: 7087-7096, 2006.

9. Pezzilli R, Bellacosa L and Felicani C: Lung injury in acute pancreatitis. JOP 10: 481-484, 2009.

10. Tomashefski JF Jr: Pulmonary pathology of the adult respiratory distress syndrome. Clin Chest Med 11: 593-619, 1990.

11. Jung KH, Song SU, Yi T, et al: Human bone marrow-derived clonal mesenchymal stem cells inhibit inflammation and reduce acute pancreatitis in rats. Gastroenterology 140: 998-1008, 2011.
12. Sánchez L, Gutierrez-Aranda I, Ligero G, et al: Enrichment of human ESC-derived multipotent mesenchymal stem cells with immunosuppressive and anti-inflammatory properties capable to protect against experimental inflammatory Bowel disease. Stem Cells 29: 251-262,2011.

13. Kubo N, Narumi S, Kijima H, Mizukami H, Yagihashi S Hakamada K and Nakane A: Efficacy of adipose tissue-derived mesenchymal stem cells for fulminant hepatitis in mice induced by concanavalin A. J Gastroenterol Hepatol 27: 165-172, 2012.

14. Choi H, Lee RH, Bazhanov N, Oh JY and Prockop DJ: Antiinflammatory protein TSG- 6 secreted by activated MSCs attenuates zymosan-induced mouse peritonitis by decreasing TLR2/NF- $\mathrm{B}$ signaling in resident macrophages. Blood 118: 330-338, 2011.

15. Jaffray C, Yang J, Carter G, Mendez C and Norman J: Pancreatic elastase activates pulmonary nuclear factor kappa $\mathrm{B}$ and inhibitory kappa B, mimicking pancreatitis-associated adult respiratory distress syndrome. Surgery 128: 225-231, 2000.

16. Keck T, Balcom JH IV,Fernández-del Castillo C, Antoniu BA and Warshaw AL: Matrix metalloproteinase-9 promotes neutrophil migration and alveolar capillary leakage in pancreatitis-associated lung injury in the rat. Gastroenterology 122: 188-201, 2002.

17. Bhatia M, Saluja AK, Hofbauer B, et al: Role of substance P and the neurokinin 1 receptor in acute pancreatitis andpancreatitisassociated lung injury. Proc Natl Acad Sci USA 95: 4760-4765, 1998.

18. Zhuo W, Liao L, Xu T, Wu W, Yang S and Tan J: Mesenchymal stem cells ameliorate ischemia-reperfusion-induced renal dysfunction by improving the antioxidant/oxidant balance in the ischemic kidney. Urol Int 86: 191-196, 2011.

19. Liu L, Cao JX, Sun B, et al: Mesenchymal stem cells inhibition of chronic ethanol-induced oxidative damage via upregulation of phosphatidylinositol-3-kinase/Akt and modulation of extracellular signal-regulated kinase 1/2 activation in PC12 cells and neurons. Neuroscience 167: 1115-1124, 2010.

20. Li ZF, Xia XM, Huang C, Zhang S, Zhang J and Zhang AJ: Emodin and baicalein inhibit pancreatic stromal derived factor-1 expression in rats with acute pancreatitis. Hepatobiliary Pancreat Dis Int 8: 201-208, 2009.

21. Yang H, Wen Y, Bin J, Hou-You Y and Yu-Tong W: Protection of bone marrow mesenchymal stem cells from acute lung injury induced by paraquat poisoning. Clin Toxicol (Phila) 49: 298-302, 2011.

22. Saito S, Nakayama T, Hashimoto N, et al: Mesenchymal stem cells stably transduced with a dominant-negative inhibitor of CCL2 greatly attenuate bleomycin-induced lung damage. Am J Pathol 179: 1088-1094, 2011.

23. Wu L, Wang G, Qu P, Yan C and Du H: Overexpression of dominant negative peroxisome proliferator-activated receptor- $\gamma$ $(\mathrm{PPAR} \gamma)$ in alveolar type II epithelial cells causes inflammation and T-cell suppression in the lung. Am J Pathol 178: 2191-2204, 2011. 